\title{
Duration from Wound Occurrence to Referral to a Vascular Center in Japanese Patients with Critical Limb Ischemia
}

\author{
Mitsuyoshi Takahara, MD, PhD, 1,2 Osamu lida, MD, ${ }^{3}$ Yoshimitsu Soga, MD, PhD, 4 \\ Akio Kodama, MD, PhD, ${ }^{5}$ Hiroto Terashi, MD, PhD, ${ }^{6}$ Makoto Utsunomiya, MD, PhD, ${ }^{7}$ \\ Jin Okazaki, MD, PhD, ${ }^{8}$ Nobuyoshi Azuma, MD, PhD, ${ }^{9}$ for the SPINACH study investigators
}

Objective: Clinical guidelines have long recommended referring patients with clerical limb ischemia (CLI) to a vascular specialist early in the course of their disease to plan for revascularization options. However, no data were so far available on how promptly CLI patients were referred to a vascular center in the real-world settings in Japan. This study aimed to survey the duration from wound occurrence to referral to a vascular center in CLI patients in Japan.

Materials and Methods: We analyzed a database of a prospective, multicenter registry in Japan, including 428 CLI patients presenting ischemic wounds and referred to

${ }^{1}$ Department of Metabolic Medicine, Osaka University Graduate School of Medicine, Suita, Osaka, Japan

${ }^{2}$ Department of Diabetes Care Medicine, Osaka University Graduate School of Medicine, Suita, Osaka, Japan

${ }^{3}$ Cardiovascular Center, Kansai Rosai Hospital, Amagasaki, Hyogo, Japan

${ }^{4}$ Department of Cardiology, Kokura Memorial Hospital, Kitakyushu, Fukuoka, Japan

${ }_{5}^{5}$ Division of Vascular Surgery, Department of Surgery, Nagoya University Graduate School of Medicine, Nagoya, Aichi, Japan ${ }^{6}$ Department of Plastic Surgery, Kobe University Graduate School of Medicine, Kobe, Hyogo, Japan

${ }^{7}$ Division of Cardiovascular Medicine, Toho University, Ohashi Medical Center, Tokyo, Japan

${ }^{8}$ Department of Vascular Surgery, Kokura Memorial Hospital, Kitakyushu, Fukuoka, Japan

${ }^{9}$ Department of Vascular Surgery, Asahikawa Medical University, Asahikawa, Hokkaido, Japan

Received: August 21, 2019; Accepted: October 25, 2019 Corresponding author: Osamu Iida, MD. Cardiovascular Center, Kansai Rosai Hospital, 3-1-69 Inabaso, Amagasaki, Hyogo 660-8511, Japan

Tel: +81-6-6416-1221, Fax: +81-6-6419-1870

E-mail: iida.osa@gmail.com

(cc) BY-NC-SA (92020 The Editorial Committee of Annals of Vascular Diseases. This article is distributed under the terms of the Creative Commons Attribution License, which permits use, distribution, and reproduction in any medium, provided the credit of the original work, a link to the license, and indication of any change are properly given, and the original work is not used for commercial purposes. Remixed or transformed contributions must be distributed under the same license as the original. vascular centers. The duration of the wound occurrence was surveyed at registration.

Results: The wound duration exceeded 1 month in $58.2 \%$ [95\% confidence interval: $53.2 \%$ to $63.1 \%$ ] of the patients, and 3 months (i.e., one season) in 15.9\% [12.4\% to $19.4 \%]$. No clinical features were significantly associated with the wound duration. The wound duration was independently associated with the wound severity evaluated using the Wound, Ischemia, and foot Infection classification system $(P=0.030)$.

Conclusion: A substantial number of CLI patients referred to vascular centers had a long duration of wounds, i.e., time from wound occurrence to the referral.

Keywords: critical limb ischemia, duration of wound, referral, wound severity

\section{Introduction}

Critical limb ischemia (CLI) is the most advanced form of peripheral arterial disease and has an extremely poor limb prognosis. Most patients with CLI will ultimately need a revascularization procedure for limb salvage. Clinical guidelines have long recommended early recognition of tissue loss and/or infection and referral to a vascular specialist; CLI patients should be referred to a vascular specialist early in the course of their disease to plan for revascularization options. ${ }^{1,2)}$ However, no data were so far available on how promptly CLI patients were referred to a vascular center in the real-world settings in Japan. The current study aimed to survey the duration from wound occurrence to referral to a vascular center in CLI patients in Japan.

\section{Materials and Methods}

We used a clinical database obtained from the Surgical Reconstruction versus Peripheral Intervention in patients with CLI (SPINACH) study, a prospective, multicenter, observational study that registered patients who had CLI 
due to atherosclerotic arterial disease in 23 centers (12 vascular surgery departments and 11 interventional cardiology departments) in Japan. CLI patients were registered at the referral to the participating centers between January 2012 and March 2013. The details of the SPINACH study are described elsewhere. ${ }^{3,4)}$ The study was performed in accordance with the Declaration of Helsinki and was approved by the ethics committee at the principal research institution, Asahikawa University Hospital (no. 1023), and all the other centers registering patients. Written informed consent was obtained. In patients presenting ischemic wounds, the duration of the wound was assessed at registration. The current analysis included a total of 428 patients who presented ischemic wounds, satisfying the Wound grade 1 or higher and Ischemia grade 2 or higher of the Wound, Ischemia, and foot Infection (WIfI) classification system. ${ }^{5)}$ Patients who underwent pre-referral revascularization after the current wound occurrence were excluded. Surgical reconstruction and endovascular therapy were scheduled in 142 and 275 patients, respectively, whereas the remaining 11 patients were not indicated for revascularization. The duration of the wound was defined as the time from the wound occurrence to the referral, based on self-report and medical records. The data on the duration of the wound were available in 388 of $428 \mathrm{pa}-$ tients $(90.1 \%)$. As mentioned elsewhere, ${ }^{4)}$ the WIfI classes of the study participants were retrospectively determined using the photographs of pedal wounds and medical records, including laboratory examinations, at registration. The judgment was first made at each participating center and was thereafter reviewed by an independent plastic surgeon. Disagreements were discussed and resolved in a subsequent committee attended by the plastic surgeon, a vascular surgeon, and an interventional cardiologist. Skin perfusion pressures of $31-40 \mathrm{mmHg}$ and $\leq 30 \mathrm{mmHg}$ were treated as WIfI Ischemia grades 2 and 3, respective$\left.1 y .{ }^{4}\right)$ The pressure sensation of the foot was assessed by the Semmes-Weinstein 5.07 monofilament at the following four podalic sites: the distal great toe and the first, third, and fifth metatarsal heads. $\left.{ }^{6}\right)$ Loss of pressure sensation was defined when patients were unable to feel correctly the pressure applied by the monofilament at any of the sites. Major cardiovascular diseases were defined as coronary artery disease and/or ischemic stroke. Prior history of lower limb revascularization and amputation was referred to as the treatments before the current wound occurrence, whether ipsilateral or not. Note again that this study did not include patients who underwent pre-referral revascularization after the current wound occurrence.

\section{Statistical analysis}

Data are given as means and standard deviations for continuous variables or as percentages for discrete vari- ables, if not otherwise mentioned. A P value of $<0.05$ was considered statistically significant, and $95 \%$ confidence intervals are reported when appropriate. The $95 \%$ confidence interval of a crude prevalence was calculated based on the binomial distribution. The association between the duration of the wound and the prevalence of respective clinical features was assessed using the generalized linear mixed model with a logit link function in which the log-transformed duration of the wound was entered as the fixed effects, and the inter-institution variability was treated as the random effects. The cumulative link mixed model with a logit link function was adopted to explore the association of the duration of the wound, as well as clinical features, with the WIfI severity. The duration of the wound was entered into the model as the fixed effects after its log-transformation. The inter-institution variability was entered as the random effect in the model. Finally, the impact of the duration of the wound on achieving a wound- and amputation-free survival after revascularization was investigated in the subgroup undergoing revascularization. The investigation was performed using the generalized linear mixed model with a logit link function, including survival with freedom from both wound and major amputation at 1, 3, 6, and 12 months after revascularization as the dependent variables, the logtransformed duration of wound as the fixed effects, and revascularization strategy (surgical or endovascular), time of follow-ups (1, 3, 6, or 12 months), and the inter-subject variability as the random effects. The WIfI Wound grade was, thereafter, additionally entered as the fixed effects to investigate whether the association of the duration of the wound with wound- and amputation-free survival was independent of the wound severity. The multiple imputation method was adopted for missing data. All statistical analyses were performed using R version 3.6.0 (R Development Core Team, Vienna, Austria).

\section{Results}

Background characteristics of the study population are shown in Table 1. Mean age was $73 \pm 10$ years; $29.0 \%$ were aged 80 years or older. The prevalence of diabetes mellitus and regular dialysis, major cardiovascular disease, and loss of pressure sensation was $73.6 \%, 53.7 \%$, $52.8 \%$, and $40.0 \%$, respectively. In diabetic patients, $15.0 \%$ had hemoglobin A1c levels $\geq 8 \%$, and $61.3 \%$ had a duration of diabetes $\geq 20$ years. Before the current wound occurrence, $24.8 \%$ of the overall population underwent lower limb revascularization, whereas $12.1 \%$ had a history of lower limb amputation. The WIfI Wound grade 3 and Ischemia grade 3 accounted for $16.8 \%$ and $80.1 \%$, respectively, whereas foot infection was observed in almost half of the population. 
Table 1 Characteristics of the study population

\begin{tabular}{|c|c|}
\hline$N$ & 428 \\
\hline Male sex & $289(67.5 \%)$ \\
\hline Age (years) & $73 \pm 10$ \\
\hline$\geq 80$ years & $124(29.0 \%)$ \\
\hline Non-ambulatory status & $210(49.1 \%)$ \\
\hline Receiving welfare & $46(10.7 \%)$ \\
\hline Living alone & $68(15.9 \%)$ \\
\hline Staying in nursing home & $35(8.2 \%)$ \\
\hline Albumin $(\mathrm{g} / \mathrm{dl})$ & $3.5 \pm 0.6$ \\
\hline$<3 \mathrm{~g} / \mathrm{dl}$ & $72(17.1 \%)$ \\
\hline Diabetes mellitus & $315(73.6 \%)$ \\
\hline $\mathrm{HbA} 1 \mathrm{c}(\%)$ & $6.7 \pm 1.3$ \\
\hline$\geq 8 \%$ & $47(15.0 \%)$ \\
\hline Duration of diabetes (years) & $23 \pm 13$ \\
\hline$\geq 20$ years & $149(61.3 \%)$ \\
\hline Regular dialysis & $230(53.7 \%)$ \\
\hline Major cardiovascular disease & $226(52.8 \%)$ \\
\hline Aspirin use & $278(65.0 \%)$ \\
\hline Thienopyridine use & $147(34.3 \%)$ \\
\hline Cilostazol use & $126(29.4 \%)$ \\
\hline Anticoagulant use & $71(16.6 \%)$ \\
\hline Loss of pressure sensation & $144(40.0 \%)$ \\
\hline Past history of intermittent claudication & $213(49.9 \%)$ \\
\hline Past history of lower limb revascularization & $106(24.8 \%)$ \\
\hline Past history of lower limb amputation & $51(12.1 \%)$ \\
\hline \multicolumn{2}{|l|}{ WIfl classification: Wound } \\
\hline W-1 & $157(36.7 \%)$ \\
\hline W-2 & $199(46.5 \%)$ \\
\hline W-3 & $72(16.8 \%)$ \\
\hline \multicolumn{2}{|l|}{ WIfI classification: Ischemia } \\
\hline $\mathrm{I}-2$ & $85(19.9 \%)$ \\
\hline $\mathrm{I}-3$ & $343(80.1 \%)$ \\
\hline \multicolumn{2}{|l|}{ WIfI classification: foot Infection } \\
\hline $\mathrm{fl}-0$ & $222(51.9 \%)$ \\
\hline $\mathrm{fl}-1$ & $104(24.3 \%)$ \\
\hline $\mathrm{fl}-2$ & $89(20.8 \%)$ \\
\hline $\mathrm{fl}-3$ & $13(3.0 \%)$ \\
\hline
\end{tabular}

Data are mean \pm standard deviation, or number (percentage). Data were unavailable on albumin levels in 8 patients $(1.9 \%)$, on $\mathrm{HbA} 1 \mathrm{c}$ levels in 2 diabetic patients $(0.6 \%)$, on duration of diabetes in 72 diabetic patients $(22.9 \%)$, on pressure sensation in 68 patients $(15.8 \%)$, history of claudication in 1 patient $(0.2 \%)$, and history of amputation before the current wound occurrence in 6 patients $(1.4 \%)$.

As demonstrated in Table 2 , only $41.8 \%$ of the overall population had a $\leq 1$-month duration of the wound. The $95 \%$ confidence interval of the prevalence was calculated to be $36.9 \%$ to $46.8 \%$. In other words, $58.2 \%$ [ $95 \%$ confidence interval: $53.2 \%$ to $63.1 \%$ ] had the duration of the wound longer than 1 month. Furthermore, the duration of the wound exceeded 3 months (i.e., one season) in 15.9\% [12.4\% to $19.4 \%$ ] of the patients. None of the clinical features (including diabetes and regular dialysis, as well as a history of lower limb treatment) were significantly associated with the duration of the wound (Table 3 ).

The association of the duration of the wound with the WIfI classes is shown in Table 4. The duration of the wound was significantly associated with the WIfI Wound severity, even after adjustment for clinical features; the adjusted odds ratio was 1.22 [1.02 to 1.47$](\mathrm{P}=0.030)$. On the other hand, the duration of the wound was not significantly associated with the WIfI Ischemia or Foot Infection severity.

Finally, the duration of the wound was significantly inversely associated with achieving a wound- and amputation-free survival after revascularization, independently of revascularization strategy; the odds ratio of the wound duration with adjustment for revascularization strategy was 0.73 [0.54 to 1.00$]$ per two-fold increase $(\mathrm{P}=0.0495)$. However, the association was no longer significant after further adjustment for the WIfI Wound severity; the adjusted odds ratio was 0.78 [0.58 to 1.06] per two-fold increase $(\mathrm{P}=0.11)$, whereas the WIfI Wound severity itself had a significant association (odds ratio: 0.33 [0.21 to 0.53 ], $\mathrm{P}<0.001$ ).

\section{Discussion}

The current study demonstrated that the duration of wound was longer than 1 month in $58.2 \%$ [53.2\% to $63.1 \%]$ of the CLI patients and exceeded 3 months (i.e., one season) in $15.9 \%$ [ $12.4 \%$ to $19.4 \%$ ], indicating that a substantial number of patients failed to be referred early to a vascular specialist. Although the true underlying causes for this delayed referral remained unexplored, limited awareness of the disease in both public and general physicians ${ }^{7,8)}$ might provoke the delay. The subsequent analysis showed that no clinical features were significantly associated with the duration of the wound, suggesting that a delayed referral would be a general issue encountered in every healthcare situation, rather than in some specific populations.

Intuitively, diabetic patients, especially with neuropathy, are more apt to leave their wounds uncared and be late in consulting doctors. However, the current study showed that the duration of the wound was not different between diabetic and non-diabetic patients, or between those with and without loss of pressure sensation, indicating that the delayed referral was similarly observed even in non-diabetic patients and those without neuropathy. Although the true reasons remained unknown, the delay might be caused mainly by the unawareness of family doctors, rather than by the nature of the disease. Another possible explanation is that patients free from diabetes and neuropathy might have had poorer knowledge on the risks of unhealed foot ulcers and their clinical significance. 
Table 2 Duration of wound in overall population and by scheduled treatment strategy

\begin{tabular}{lccccc}
\hline \multicolumn{1}{c}{ Duration of wound } & \multicolumn{1}{c}{ s month } & $1-2$ months & $2-3$ months & 3-6 months & $>6$ months \\
\hline Overall $(n=428)$ & $41.8 \%[36.9 \%-46.8 \%]$ & $22.1 \%[17.9 \%-26.2 \%]$ & $20.2 \%[16.0 \%-24.5 \%]$ & $11.7 \%[8.5 \%-14.8 \%]$ & $4.2 \%[2.2 \%-6.2 \%]$ \\
Surgical $(n=142)$ & $38.0 \%[28.9 \%-47.1 \%]$ & $22.7 \%[15.4 \%-30.0 \%]$ & $20.6 \%[12.9 \%-28.2 \%]$ & $13.4 \%[7.3 \%-19.6 \%]$ & $5.3 \%[1.3 \%-9.3 \%]$ \\
Endovascular $(n=275)$ & $44.3 \%[38.3 \%-50.3 \%]$ & $21.0 \%[16.0 \%-26.0 \%]$ & $19.9 \%[14.9 \%-24.8 \%]$ & $11.1 \%[7.2 \%-14.9 \%]$ & $3.7 \%[1.5 \%-6.0 \%]$ \\
Conservative $(n=11)$ & $36.4 \%[7.9 \%-64.8 \%]$ & $27.3 \%[1.0 \%-53.6 \%]$ & $18.2 \%[0.0 \%-41.0 \%]$ & $9.1 \%[0.0 \%-26.1 \%]$ & $9.1 \%[0.0 \%-26.1 \%]$ \\
\hline
\end{tabular}

Data are the estimated proportions [ $95 \%$ confidence intervals] obtained using the multiple imputation methods. The original data on the duration of the wound were available in 388 of 428 patients (90.1\%): 117 of 142 surgical patients (82.4\%), 260 of 275 endovascular patients (94.5\%), and 11 of 11 conservative patients $(100.0 \%)$. The duration of the wound were not different among scheduled treatment strategies $(P=0.31$ between surgical and endovascular, $\mathrm{P}=0.48$ between surgical and conservative, and $\mathrm{P}=0.38$ between endovascular and conservative, by the linear mixed model including log-transformed duration of wound as the dependent variable, treatment strategies as the fixed effects, and the inter-institution variability as the random effects).

Table 3 Association between duration of wound and clinical features

\begin{tabular}{|c|c|c|c|c|c|c|}
\hline Duration of wound & $\leq 1$ month & $1-2$ months & 2-3 months & 3-6 months & $>6$ months & $\mathrm{P}$ \\
\hline Male sex & $\begin{array}{c}69.8 \% \\
{[65.4 \%-74.3 \%]}\end{array}$ & $\begin{array}{c}66.1 \% \\
{[61.2 \%-71.0 \%]}\end{array}$ & $\begin{array}{c}64.0 \% \\
{[59.1 \%-68.8 \%]}\end{array}$ & $\begin{array}{c}62.8 \% \\
{[55.4 \%-70.1 \%]}\end{array}$ & $\begin{array}{c}82.4 \% \\
{[70.5 \%-94.2 \%]}\end{array}$ & 0.84 \\
\hline Age $\geq 80$ years & $\begin{array}{c}29.4 \% \\
{[24.7 \%-34.0 \%]}\end{array}$ & $\begin{array}{c}26.7 \% \\
{[21.4 \%-32.0 \%]}\end{array}$ & $\begin{array}{c}26.5 \% \\
{[21.4 \%-31.7 \%]}\end{array}$ & $\begin{array}{c}32.0 \% \\
{[25.5 \%-38.5 \%]}\end{array}$ & $\begin{array}{c}40.0 \% \\
{[30.2 \%-49.7 \%]}\end{array}$ & 0.41 \\
\hline Non-ambulatory status & $\begin{array}{c}50.4 \% \\
{[45.4 \%-55.4 \%]}\end{array}$ & $\begin{array}{c}51.3 \% \\
{[45.6 \%-56.9 \%]}\end{array}$ & $\begin{array}{c}46.0 \% \\
{[41.0 \%-50.9 \%]}\end{array}$ & $\begin{array}{c}46.4 \% \\
{[40.2 \%-52.5 \%]}\end{array}$ & $\begin{array}{c}46.6 \% \\
{[33.2 \%-59.9 \%]}\end{array}$ & 0.97 \\
\hline Receiving welfare & $\begin{array}{c}13.1 \% \\
{[9.7 \%-16.4 \%]}\end{array}$ & $\begin{array}{c}11.4 \% \\
{[6.8 \%-16.1 \%]}\end{array}$ & $\begin{array}{c}8.1 \% \\
{[4.6 \%-11.5 \%]}\end{array}$ & $\begin{array}{c}7.2 \% \\
{[1.6 \%-12.8 \%]}\end{array}$ & $\begin{array}{c}6.7 \% \\
{[0.0 \%-14.1 \%]}\end{array}$ & 0.50 \\
\hline Living alone & $\begin{array}{c}16.5 \% \\
{[12.9 \%-20.1 \%]}\end{array}$ & $\begin{array}{c}18.2 \% \\
{[14.1 \%-22.3 \%]}\end{array}$ & $\begin{array}{c}15.7 \% \\
{[11.0 \%-20.3 \%]}\end{array}$ & $\begin{array}{c}14.0 \% \\
{[8.5 \%-19.6 \%]}\end{array}$ & $\begin{array}{c}3.3 \% \\
{[0.0 \%-18.2 \%]}\end{array}$ & 0.52 \\
\hline Staying in nursing home & $\begin{array}{c}9.2 \% \\
{[6.3 \%-12.0 \%]}\end{array}$ & $\begin{array}{c}10.6 \% \\
{[7.6 \%-13.6 \%]}\end{array}$ & $\begin{array}{c}3.9 \% \\
{[1.7 \%-6.1 \%]}\end{array}$ & $\begin{array}{c}6.4 \% \\
{[3.4 \%-9.4 \%]}\end{array}$ & $\begin{array}{c}11.2 \% \\
{[7.6 \%-14.7 \%]}\end{array}$ & 0.53 \\
\hline Albumin $<3 \mathrm{~g} / \mathrm{dl}$ & $\begin{array}{c}18.8 \% \\
{[14.9 \%-22.7 \%]}\end{array}$ & $\begin{array}{c}15.2 \% \\
{[10.5 \%-20.0 \%]}\end{array}$ & $\begin{array}{c}16.8 \% \\
{[12.0 \%-21.6 \%]}\end{array}$ & $\begin{array}{c}20.4 \% \\
{[16.3 \%-24.5 \%]}\end{array}$ & $\begin{array}{c}3.3 \% \\
{[0.0 \%-12.2 \%]}\end{array}$ & 0.89 \\
\hline Diabetes mellitus & $\begin{array}{c}73.5 \% \\
{[68.6 \%-78.4 \%]}\end{array}$ & $\begin{array}{c}73.1 \% \\
{[65.5 \%-80.8 \%]}\end{array}$ & $\begin{array}{c}71.3 \% \\
{[66.6 \%-76.1 \%]}\end{array}$ & $\begin{array}{c}78.1 \% \\
{[70.3 \%-85.9 \%]}\end{array}$ & $\begin{array}{c}75.5 \% \\
{[67.1 \%-84.0 \%]}\end{array}$ & 0.61 \\
\hline $\mathrm{HbA} 1 \mathrm{c} \geq 8 \%$ & $\begin{array}{c}12.3 \% \\
{[9.0 \%-15.6 \%]}\end{array}$ & $\begin{array}{c}11.9 \% \\
{[8.5 \%-15.2 \%]}\end{array}$ & $\begin{array}{c}10.4 \% \\
{[7.4 \%-13.5 \%]}\end{array}$ & $\begin{array}{c}8.0 \% \\
{[5.4 \%-10.6 \%]}\end{array}$ & $\begin{array}{c}5.6 \% \\
{[3.2 \%-7.9 \%]}\end{array}$ & 0.12 \\
\hline Duration $\geq 20$ years & $\begin{array}{c}44.5 \% \\
{[37.9 \%-51.1 \%]}\end{array}$ & $\begin{array}{c}42.6 \% \\
{[29.6 \%-55.6 \%]}\end{array}$ & $\begin{array}{c}50.1 \% \\
{[42.5 \%-57.8 \%]}\end{array}$ & $\begin{array}{c}41.6 \% \\
{[35.9 \%-47.3 \%]}\end{array}$ & $\begin{array}{c}41.1 \% \\
{[20.3 \%-62.0 \%]}\end{array}$ & 0.94 \\
\hline Regular dialysis & $\begin{array}{c}54.0 \% \\
{[48.5 \%-59.5 \%]}\end{array}$ & $\begin{array}{c}57.2 \% \\
{[50.7 \%-63.7 \%]}\end{array}$ & $\begin{array}{c}51.1 \% \\
{[44.3 \%-57.9 \%]}\end{array}$ & $\begin{array}{c}50.9 \% \\
{[39.8 \%-61.9 \%]}\end{array}$ & $\begin{array}{c}54.5 \% \\
{[45.0 \%-64.0 \%]}\end{array}$ & 0.84 \\
\hline Major cardiovascular disease & $\begin{array}{c}57.6 \% \\
{[52.0 \%-63.2 \%]}\end{array}$ & $\begin{array}{c}53.8 \% \\
{[46.8 \%-60.8 \%]}\end{array}$ & $\begin{array}{c}36.5 \% \\
{[31.6 \%-41.4 \%]}\end{array}$ & $\begin{array}{c}59.2 \% \\
{[52.8 \%-65.5 \%]}\end{array}$ & $\begin{array}{c}61.1 \% \\
{[51.4 \%-70.8 \%]}\end{array}$ & 0.55 \\
\hline Loss of pressure sensation & $\begin{array}{c}39.2 \% \\
{[33.8 \%-44.6 \%]}\end{array}$ & $\begin{array}{c}34.7 \% \\
{[28.1 \%-41.4 \%]}\end{array}$ & $\begin{array}{c}49.0 \% \\
{[40.8 \%-57.2 \%]}\end{array}$ & $\begin{array}{c}41.6 \% \\
{[31.3 \%-51.9 \%]}\end{array}$ & $\begin{array}{c}46.6 \% \\
{[27.6 \%-65.6 \%]}\end{array}$ & 0.74 \\
\hline History of claudication & $\begin{array}{c}56.4 \% \\
{[51.6 \%-61.2 \%]}\end{array}$ & $\begin{array}{c}46.0 \% \\
{[38.8 \%-53.1 \%]}\end{array}$ & $\begin{array}{c}43.0 \% \\
{[38.0 \%-47.9 \%]}\end{array}$ & $\begin{array}{c}41.2 \% \\
{[33.3 \%-49.1 \%]}\end{array}$ & $\begin{array}{c}63.3 \% \\
{[56.5 \%-70.1 \%]}\end{array}$ & 0.42 \\
\hline History of revascularization & $\begin{array}{c}25.6 \% \\
{[21.1 \%-30.1 \%]}\end{array}$ & $\begin{array}{c}28.8 \% \\
{[23.5 \%-34.1 \%]}\end{array}$ & $\begin{array}{c}24.0 \% \\
{[18.6 \%-29.4 \%]}\end{array}$ & $\begin{array}{c}19.2 \% \\
{[11.0 \%-27.4 \%]}\end{array}$ & $\begin{array}{c}14.4 \% \\
{[7.1 \%-21.6 \%]}\end{array}$ & 0.25 \\
\hline History of amputation & $\begin{array}{c}13.5 \% \\
{[10.0 \%-17.0 \%]}\end{array}$ & $\begin{array}{c}11.5 \% \\
{[7.6 \%-15.3 \%]}\end{array}$ & $\begin{array}{c}11.1 \% \\
{[7.1 \%-15.1 \%]}\end{array}$ & $\begin{array}{c}16.0 \% \\
{[11.8 \%-20.1 \%]}\end{array}$ & $\begin{array}{c}7.7 \% \\
{[0.0 \%-16.2 \%]}\end{array}$ & 0.88 \\
\hline
\end{tabular}

Data are estimated prevalence with $95 \%$ confidence intervals, as well as $\mathrm{P}$ values for trend, obtained from the generalized linear mixed model with a logit link function.

If such poor knowledge on foot ischemia underlies the delay, raising medical and public awareness of the disease could be a realistic solution to accelerate their referral to a vascular center.

Another paradoxical finding of the current study was that a history of lower limb revascularization was not associated with a shortened duration of wound. Generally, patients with history of lower limb revascularization, i.e., those previously diagnosed with peripheral artery disease, are more likely suspected of having the risk of foot 
Table 4 Association of clinical features with wound severity

\begin{tabular}{|c|c|c|c|c|c|c|}
\hline & \multicolumn{2}{|c|}{ WIfl: Wound severity } & \multicolumn{2}{|c|}{ WIfl: Ischemia severity } & \multicolumn{2}{|c|}{ WIfl: foot Infection severity } \\
\hline & Crude OR & Adjusted OR & Crude OR & Adjusted OR & Crude OR & Adjusted OR \\
\hline Male sex & $\begin{array}{c}0.88 \\
{[0.59-1.32]}\end{array}$ & $\begin{array}{c}0.96 \\
{[0.62-1.48]}\end{array}$ & $\begin{array}{c}1.01 \\
{[0.60-1.70]}\end{array}$ & $\begin{array}{c}1.00 \\
{[0.57-1.74]}\end{array}$ & $\begin{array}{c}0.73 \\
{[0.48-1.10]}\end{array}$ & $\begin{array}{c}0.79 \\
{[0.51-1.23]}\end{array}$ \\
\hline Age $\geq 80$ years & $\begin{array}{c}0.85 \\
{[0.56-1.29]}\end{array}$ & $\begin{array}{c}0.87 \\
{[0.55-1.38]}\end{array}$ & $\begin{array}{c}1.28 \\
{[0.73-2.24]}\end{array}$ & $\begin{array}{c}1.38 \\
{[0.74-2.58]}\end{array}$ & $\begin{array}{c}0.89 \\
{[0.58-1.35]}\end{array}$ & $\begin{array}{c}0.86 \\
{[0.54-1.36]}\end{array}$ \\
\hline Non-ambulatory status & $\begin{array}{c}1.95 \\
{[1.32-2.89]^{*}}\end{array}$ & $\begin{array}{c}1.72 \\
{[1.11-2.65]^{*}}\end{array}$ & $\begin{array}{c}0.84 \\
{[0.51-1.38]}\end{array}$ & $\begin{array}{c}0.98 \\
{[0.56-1.71]}\end{array}$ & $\begin{array}{c}1.48 \\
{[1.00-2.18]}\end{array}$ & $\begin{array}{c}1.18 \\
{[0.76-1.83]}\end{array}$ \\
\hline Receiving welfare & $\begin{array}{c}1.16 \\
{[0.63-2.13]}\end{array}$ & $\begin{array}{c}1.09 \\
{[0.55-2.15]}\end{array}$ & $\begin{array}{c}0.63 \\
{[0.31-1.31]}\end{array}$ & $\begin{array}{c}0.72 \\
{[0.32-1.62]}\end{array}$ & $\begin{array}{c}0.76 \\
{[0.40-1.45]}\end{array}$ & $\begin{array}{c}0.68 \\
{[0.34-1.38]}\end{array}$ \\
\hline Living alone & $\begin{array}{c}1.18 \\
{[0.70-1.98]}\end{array}$ & $\begin{array}{c}1.14 \\
{[0.64-2.03]}\end{array}$ & $\begin{array}{c}0.91 \\
{[0.47-1.78]}\end{array}$ & $\begin{array}{c}0.99 \\
{[0.46-2.10]}\end{array}$ & $\begin{array}{c}0.87 \\
{[0.51-1.49]}\end{array}$ & $\begin{array}{c}0.88 \\
{[0.48-1.59]}\end{array}$ \\
\hline Staying in nursing home & $\begin{array}{c}1.14 \\
{[0.56-2.33]}\end{array}$ & $\begin{array}{c}0.74 \\
{[0.33-1.66]}\end{array}$ & $\begin{array}{c}0.75 \\
{[0.31-1.79]}\end{array}$ & $\begin{array}{c}0.82 \\
{[0.31-2.17]}\end{array}$ & $\begin{array}{c}1.23 \\
{[0.60-2.54]}\end{array}$ & $\begin{array}{c}1.14 \\
{[0.51-2.57]}\end{array}$ \\
\hline Albumin $<3 \mathrm{~g} / \mathrm{dl}$ & $\begin{array}{c}2.83 \\
{[1.69-4.74]^{*}}\end{array}$ & $\begin{array}{c}2.64 \\
{[1.54-4.54]^{*}}\end{array}$ & $\begin{array}{c}0.88 \\
{[0.45-1.70]}\end{array}$ & $\begin{array}{c}0.94 \\
{[0.47-1.90]}\end{array}$ & $\begin{array}{c}1.99 \\
{[1.20-3.29]^{*}}\end{array}$ & $\begin{array}{c}1.82 \\
{[1.07-3.11]^{*}}\end{array}$ \\
\hline Diabetes with $\mathrm{HbA} 1 \mathrm{c}<8 \%$ & $\begin{array}{c}1.28 \\
{[0.82-1.99]}\end{array}$ & $\begin{array}{c}1.23 \\
{[0.66-2.29]}\end{array}$ & $\begin{array}{c}0.71 \\
{[0.39-1.27]}\end{array}$ & $\begin{array}{c}1.37 \\
{[0.62-3.04]}\end{array}$ & $\begin{array}{c}1.76 \\
{[1.11-2.79]^{*}}\end{array}$ & $\begin{array}{c}1.27 \\
{[0.68-2.35]}\end{array}$ \\
\hline Diabetes with $\mathrm{HbA} 1 \mathrm{c} \geq 8 \%$ & $\begin{array}{c}2.15 \\
{[1.11-4.16]^{*}}\end{array}$ & $\begin{array}{c}2.26 \\
{[1.01-5.04]^{*}}\end{array}$ & $\begin{array}{c}1.26 \\
{[0.46-3.45]}\end{array}$ & $\begin{array}{c}2.51 \\
{[0.76-8.27]}\end{array}$ & $\begin{array}{c}1.77 \\
{[0.90-3.50]}\end{array}$ & $\begin{array}{c}1.26 \\
{[0.54-2.93]}\end{array}$ \\
\hline Duration of diabetes $\geq 20$ years & $\begin{array}{c}0.96 \\
{[0.60-1.54]}\end{array}$ & $\begin{array}{c}0.68 \\
{[0.36-1.29]}\end{array}$ & $\begin{array}{c}0.62 \\
{[0.36-1.05]}\end{array}$ & $\begin{array}{c}0.60 \\
{[0.29-1.26]}\end{array}$ & $\begin{array}{c}1.66 \\
{[1.05-2.62]^{*}}\end{array}$ & $\begin{array}{c}1.34 \\
{[0.77-2.33]}\end{array}$ \\
\hline Regular dialysis & $\begin{array}{c}0.95 \\
{[0.65-1.39]}\end{array}$ & $\begin{array}{c}0.91 \\
{[0.59-1.40]}\end{array}$ & $\begin{array}{c}0.87 \\
{[0.53-1.42]}\end{array}$ & $\begin{array}{c}1.09 \\
{[0.62-1.91]}\end{array}$ & $\begin{array}{c}1.06 \\
{[0.72-1.57]}\end{array}$ & $\begin{array}{c}1.02 \\
{[0.66-1.59]}\end{array}$ \\
\hline Major cardiovascular disease & $\begin{array}{c}0.94 \\
{[0.64-1.38]}\end{array}$ & $\begin{array}{c}0.94 \\
{[0.63-1.41]}\end{array}$ & $\begin{array}{c}0.92 \\
{[0.56-1.50]}\end{array}$ & $\begin{array}{c}0.95 \\
{[0.56-1.62]}\end{array}$ & $\begin{array}{c}0.80 \\
{[0.54-1.18]}\end{array}$ & $\begin{array}{c}0.72 \\
{[0.47-1.08]}\end{array}$ \\
\hline Loss of pressure sensation & $\begin{array}{c}1.93 \\
{[1.21-3.07]^{*}}\end{array}$ & $\begin{array}{c}1.88 \\
{[1.05-3.34]^{*}}\end{array}$ & $\begin{array}{c}0.54 \\
{[0.32-0.93]^{*}}\end{array}$ & $\begin{array}{c}0.59 \\
{[0.32-1.09]}\end{array}$ & $\begin{array}{c}1.92 \\
{[1.22-3.04]^{*}}\end{array}$ & $\begin{array}{c}1.81 \\
{[1.09-3.02]^{*}}\end{array}$ \\
\hline History of claudication & $\begin{array}{c}0.75 \\
{[0.50-1.10]}\end{array}$ & $\begin{array}{c}0.91 \\
{[0.60-1.38]}\end{array}$ & $\begin{array}{c}1.21 \\
{[0.73-1.99]}\end{array}$ & $\begin{array}{c}1.04 \\
{[0.61-1.78]}\end{array}$ & $\begin{array}{c}0.74 \\
{[0.50-1.11]}\end{array}$ & $\begin{array}{c}0.93 \\
{[0.60-1.43]}\end{array}$ \\
\hline History of revascularization & $\begin{array}{c}0.83 \\
{[0.53-1.29]}\end{array}$ & $\begin{array}{c}0.63 \\
{[0.37-1.07]}\end{array}$ & $\begin{array}{c}0.89 \\
{[0.50-1.56]}\end{array}$ & $\begin{array}{c}1.17 \\
{[0.60-2.31]}\end{array}$ & $\begin{array}{c}0.84 \\
{[0.53-1.32]}\end{array}$ & $\begin{array}{c}0.59 \\
{[0.34-1.03]}\end{array}$ \\
\hline History of amputation & $\begin{array}{c}1.76 \\
{[0.99-3.10]}\end{array}$ & $\begin{array}{c}1.88 \\
{[0.96-3.69]}\end{array}$ & $\begin{array}{c}0.48 \\
{[0.25-0.95]^{*}}\end{array}$ & $\begin{array}{c}0.46 \\
{[0.20-1.03]}\end{array}$ & $\begin{array}{c}1.88 \\
{[1.06-3.31]^{*}}\end{array}$ & $\begin{array}{c}2.12 \\
{[1.09-4.12]^{*}}\end{array}$ \\
\hline $\begin{array}{l}\text { Duration of wound } \\
\text { (per 2-fold increase) }\end{array}$ & $\begin{array}{c}1.19 \\
{[1.00-1.42]^{*}}\end{array}$ & $\begin{array}{c}1.22 \\
{[1.02-1.47]^{*}}\end{array}$ & $\begin{array}{c}0.80 \\
{[0.64-1.00]}\end{array}$ & $\begin{array}{c}0.80 \\
{[0.64-1.01]}\end{array}$ & $\begin{array}{c}1.00 \\
{[0.83-1.19]}\end{array}$ & $\begin{array}{c}0.96 \\
{[0.79-1.15]}\end{array}$ \\
\hline
\end{tabular}

Data are odds ratios (ORs) and their 95\% confidence intervals. Adjusted ORs were obtained from the multivariate model in which all variables listed in the table were entered. Asterisks indicate $\mathrm{P}<0.05$.

ischemia. The current study, however, suggested that they were not always referred to a vascular center earlier. Some patients might distinctly remember the burden and cost of the peripheral interventions they previously underwent, and might be reluctant to experience such treatments again. Such unwillingness might obstruct timely consultation. In other patients, information on the history of revascularization might not be properly shared with family doctors or care providers; the information might not be utilized for differential diagnosis in primary care.

The duration of the wound was independently associated with an increased wound severity, evaluated by the WIfI classification Wound grade. As is well documented, ischemic wounds have a progressive nature, often requiring timely revascularization. ${ }^{1,2)}$ Although the causal relationship between the duration of the wound and the wound severity remained to be proven, a delayed referral to a vascular center, until which ischemic wounds would be deteriorated, could increase the wound severity at referral. Furthermore, the duration of the wound was inversely associated with achieving a wound- and amputation-free status after revascularization. This inverse association was no longer significant after adjustment for the wound severity, indicating that the association would be explained by the wound severity. As is well recognized, CLI presenting severe tissue loss is still associated with poor limb prognosis even after successful revascularization procedures. ${ }^{9,10)}$ It is also of note that the severity in tissue loss and the prolonged time to heal both increase resource utilization and costs, which is a considerable health care burden. ${ }^{11,12)}$ 
Efforts to promote a prompt referral, shortening the duration of the wound, would potentially minimize wound severity, help achieve wound- and amputation-free status after revascularization, and reduce the health care burden. Future prospective studies are needed to validate the efficacy.

The current study had some limitations. First, the duration of the wound was based on self-report as well as medical records. Recall of the history might be at risk for inaccuracy. Second, information on the primary wound care before the referral was unavailable. The reasons why CLI patients were not referred early to a vascular center also remained unknown. Third, the SPINACH study collected data on renal failure, neuropathy, and major cardiovascular disease, but not on other diabetes-related micro- or macro-angiopathies (e.g., retinopathy and carotid artery disease), which are expected to be commonly seen in this population. ${ }^{13,14)}$ Data on primary foot care and patient education were also unavailable in the study. Fourth, the current study included only CLI patients referred to the vascular centers; no data were available on patients who developed CLI but were never referred to the vascular centers.

\section{Conclusion}

A substantial number of CLI patients referred to vascular centers had a long duration of ischemic wounds, i.e., time from wound occurrence to the referral. The duration of the wound was an independent risk factor for the wound severity, and CLI patients with a longer wound duration were less likely to achieve a wound- and amputation-free status after revascularization. There was still space for promoting a prompt referral of CLI patients to a vascular center in real-world settings in Japan.

\section{Funding}

The SPINACH Study is sponsored by Abbott Vascular Japan Co., Ltd, Boston Scientific Japan K.K., Cook Japan Incorporated, Goodman Co., Ltd, Johnson \& Johnson K.K., Kaken Pharmaceutical Co., Ltd, Kaneka Medix Corporation, Medicon Inc., Medikit Co., Ltd, Medtronic Japan Co., Ltd, Mitsubishi Tanabe Pharma Corporation, MSD K.K., St. Jude Medical Japan Co., Ltd, Taisho Toyama Pharmaceutical Co., Ltd, Terumo Corp., W. L.Gore \& Associates, Co., Ltd (in alphabetical order). The funding companies played no role in the design of the study, selection of the enrolled patients, revascularization procedures or equipment, or interpretation of the data.

\section{Disclosure Statement}

The authors declare that they have no conflict of interest.

\section{Additional Note}

Informed consent has been obtained from participants.

\section{Author Contributions}

Study conception: MT, OI, YS, AK, NA

Analysis: MT

Writing: MT, OI

Funding acquisition: NA

Critical review and revision: all authors

Final approval of the article: all authors

Accountability for all aspects of the work: all authors

\section{References}

1) Norgren L, Hiatt WR, Dormandy JA, et al. Inter-society consensus for the management of peripheral arterial disease (TASC II). Eur J Vasc Endovasc Surg 2007; 33 Suppl 1: S175.

2) Aboyans V, Ricco JB, Bartelink MEL, et al. 2017 ESC guidelines on the diagnosis and treatment of peripheral arterial diseases, in collaboration with the European Society for Vascular Surgery (ESVS): document covering atherosclerotic disease of extracranial carotid and vertebral, mesenteric, renal, upper and lower extremity arteries. Endorsed by: the European Stroke Organization (ESO), the Task Force for the Diagnosis and Treatment of Peripheral Arterial Diseases of the European Society of Cardiology (ESC) and of the European Society for Vascular Surgery (ESVS). Eur Heart J 2018; 39: 763-816.

3) Azuma N, Iida O, Takahara M, et al. Surgical reconstruction versus peripheral intervention in patients with critical limb ischemia-a prospective multicenter registry in Japan: the SPINACH study design and rationale. Vascular 2014; 22: 411-20.

4) Iida O, Takahara M, Soga Y, et al. Three-year outcomes of surgical versus endovascular revascularization for critical limb ischemia: the SPINACH study (surgical reconstruction versus peripheral intervention in patients with critical limb ischemia). Circ Cardiovasc Interv 2017; 10: e005531.

5) Mills JL Sr, Conte MS, Armstrong DG, et al. The Society for Vascular Surgery lower extremity threatened limb classification system: risk stratification based on Wound, Ischemia, and foot Infection (WIfI). J Vasc Surg 2014; 59: 220-34.e2.

6) Boulton AJ, Armstrong DG, Albert SF, et al. Comprehensive foot examination and risk assessment: a report of the task force of the foot care interest group of the American Diabetes Association, with endorsement by the American Association of Clinical Endocrinologists. Diabetes Care 2008; 31: 1679-85.

7) Lovell M, Harris K, Forbes T, et al. Peripheral arterial disease: lack of awareness in Canada. Can J Cardiol 2009; 25 : 
39-45.

8) Hirsch AT, Criqui MH, Treat-Jacobson D, et al. Peripheral arterial disease detection, awareness, and treatment in primary care. JAMA 2001; 286: 1317-24.

9) Shiraki T, Iida O, Takahara M, et al. Predictors of delayed wound healing after endovascular therapy of isolated infrapopliteal lesions underlying critical limb ischemia in patients with high prevalence of diabetes mellitus and hemodialysis. Eur J Vasc Endovasc Surg 2015; 49: 565-73.

10) Azuma N, Uchida H, Kokubo T, et al. Factors influencing wound healing of critical ischaemic foot after bypass surgery: is the angiosome important in selecting bypass target artery? Eur J Vasc Endovasc Surg 2012; 43: 322-8.
11) Reinecke $H$, Unrath $M$, Freisinger E, et al. Peripheral arterial disease and critical limb ischaemia: still poor outcomes and lack of guideline adherence. Eur Heart J 2015; 36: 932-8.

12) Fife CE, Carter MJ. Wound care outcomes and associated cost among patients treated in US outpatient wound centers: data from the US wound registry. Wounds 2012; 24: 10-7.

13) Takahara M, Iida O, Fujita Y, et al. Clinical characteristics of Japanese diabetic patients with critical limb ischemia presenting Fontaine stage IV. Diabetol Int 2019; 10: 231-5.

14) Takahara M, Okuno S, Nakamura I, et al. Prospective study on clinical characteristics of Japanese diabetic patients with chronic limb-threatening ischemia presenting Fontaine stage IV. Diabetol Int 2019. doi:10.1007/s13340-019-00399-5. 